\title{
POPULATION AVOIDANCE IN
}

\section{AIMPOINT SELECTION}

C. G. André

January 11,1978

Work performed under the auspices of the U.S. Department of

Energy by the UCLLL under contract number W-7405-ENG-48.

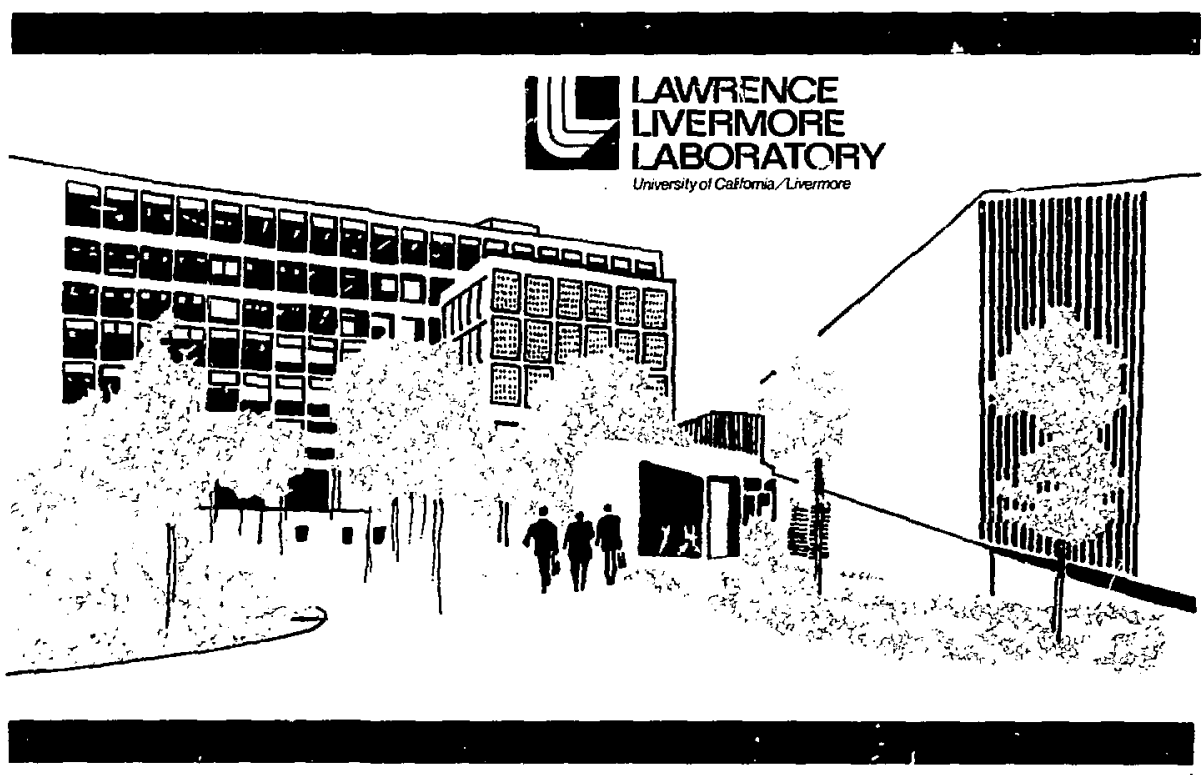


"This report wa prepured as an account of work sponsored by the United State Government. Neither the United States nor the United States Depurtment of Enersy, nor any of their employees, nor any of their contractors, nubcon. tractors, or their employeet, makes any warrenty, express or implied, or asomes any legel liebillity or responsibility for the eccuracy, completeness or usefulnes of any information, epperatus, product or process dieclosed, or represents that its use would not infringt privately.owned ifthts."

NOTICE.

b:

Reference to a company or product name does not imply approval of recommendation of the product by the University of California or the U.S. Department of Energy to the exclusion of others that may be suitable.

Printed in the Unitcd States of Americe Avalable from

National Techsieal Information Service

U.S. Depastment of Commerce

5285 Port Royal Road

Springfield, VA 2216!

Price: Printed Copy $\mathbf{S}$ : Mitrofiche $\mathbf{5 3 . 0 0}$

\begin{tabular}{|c|c|c|c|}
\hline Page Range & $\begin{array}{l}\text { Domestie } \\
\text { Prive }\end{array}$ & Page Aange & $\begin{array}{c}\text { Dorr.ustic } \\
\text { Price }\end{array}$ \\
\hline $001-025$ & S 4.00 & $326-350$ & S12.00 \\
\hline $026-G 50$ & 4.50 & $351-375$ & 12.50 \\
\hline $051-075$ & 5.25 & $376-400$ & 13.00 \\
\hline $076-100$ & 6.00 & $401-425$ & 13.25 \\
\hline $101-125$ & 6.50 & $426-450$ & 14.00 \\
\hline $126-150$ & 7.25 & $451-475$ & 14.50 \\
\hline $151-175$ & 8.00 & $476-500$ & 15.00 \\
\hline $176-200$ & 9.00 & $501-525$ & 15.25 \\
\hline $201-225$ & 9.25 & $526-550$ & 15.50 \\
\hline $226-250$ & 9.50 & $551--575$ & 16.25 \\
\hline $251-275$ & 10.75 & $576-600$ & 16.50 \\
\hline $276-300$ & 11.00 & $601-u p$ & -1 \\
\hline $301-325$ & 11.75 & & \\
\hline
\end{tabular}

Ii Add $\$ 2.50$ for esch additionad 100 puje instement from 601 papes up. 


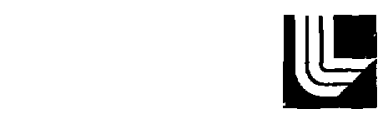

LAWRENCE LIVERMORE LABORATORY

University of Calfornia Livermore, Calítomia 94550

UCAL-52386

\title{
POPULATION AVOIDANCE IN AIMPOINT SELECTION
}

\author{
C. G. André
}

MS. date: January 11, 1978

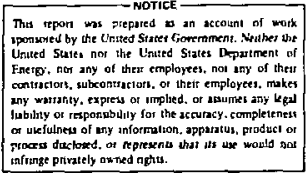




\section{CONTENTS}

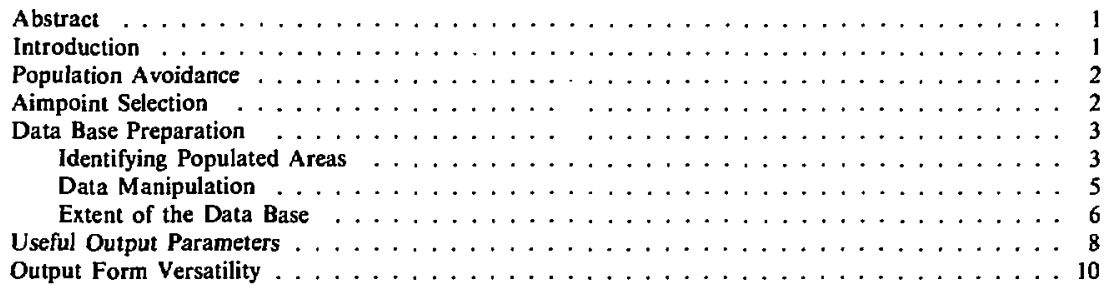

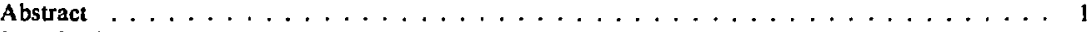

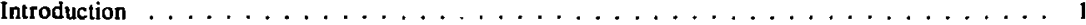

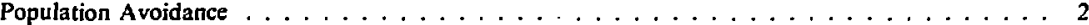

Aimpoint Selection $\ldots \ldots \ldots \ldots \ldots \ldots \ldots \ldots \ldots \ldots \ldots$

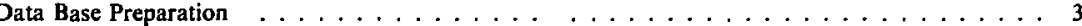

Identifying Populated Areas $\ldots \ldots \ldots \ldots \ldots \ldots \ldots$

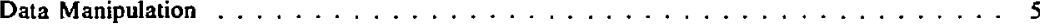

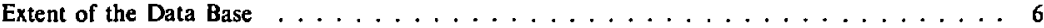

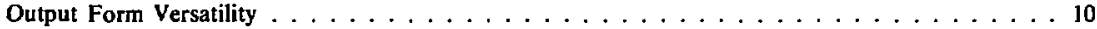




\title{
POPULATION AVOIDANCE IN AIMPOINT SELECTION
}

\begin{abstract}
In most past studies of the effectiveness of tactical nuclear weapons vs the amount of collateral damage produced (civilian casualties), civilians have been congregared into idealized shaped towns and cities, and criteria for city avoidance were usually formulated in terms relating to a town's population. This treatment was sufficient in those studies where weapon yields were so large that great numbers of civilians were almost always placed at risk. As further studies developed, demonstrating that real progress could be made in reducing the numbers of civilians potentially placed at risk in tactical nuclear warfare situations, the inadequacies of the present treatment became obvious. The need existed for a more detailed description of the distribution of civilians. The method described in this report determines the number of civilians at risk for a weapon under consideration being detonated at a given point and displays a symbol relating tc the numbers at risk on a map or a transparency that overlays a 1:50,000 map of the region. Thus, a weapons planner maiking the selection of aimpoints for inflicting the necessary military damage required has the means to reduce potential civilian casualties by properly choosing the weapon and aimpoints.
\end{abstract}

\section{INTRODUCTION}

Over the last decade, efforts were increased to reduce the potential number of civilian casualties in studies made of tactical nuclear warfare confrontations. Whereas early studies concentrated on achieving desired levels of military effectiveness with little regard to sparing civilians congregated in regions of conflict, subsequent studies usually attempted to reduce the collateral damage to civilians and their towns. Most of these studies centered on a criterion of selecting some level of town size and avoiding, or not placing at risk, those towns of a greater population. These later studies showed substantial reductions in civilian casualties and made comparisons of the relative military effectiveness of different weapons.

As the data were examined further, it became evident that the civilians destroyed were not those on the fringes of the towns where the weapon effects became lethal as the burstpoint was moved closer to the town; but rather, those that were hit directly by high level lethal eifects because their presence was essentially ignored when selecting the aimpoint, and the weapon was burst over them.

It thus became essential that if one diligently wished to examine and reduce civilian casualties, an approach could be developed that allowed for treatment of the civilian populations more expeditiously. Initially, one must be able to spare most populations from direct impacts. Secondly, one must describe the positions of civilians in more detail rather than indicate they are within a prescribed circular or rectangular shaped town or city that is centered on the centroid of the population.

This report consists of two parts: a description of the method of population avoidance and examples of its application; and the processes and codes used to generate the output and the different forms of display useful in analysis. 


\section{POPULATION AVOIDANCE}

In this report we describe a methodology that accounts for the actual population distribution of the people. There is not, per se, a dependence on towin size as in previous studies. In earlier approaches several smaller towns were often valued less than a larger town, although the civilians affected were greater. In this treatment of the provicm, the number of civilians at risk is determined for "every possible" gimpoint of a nuclear weapon.

The shapes and populations of the cities take on a balanced significance. The popu! ' ion is completely described by characterizing each sufficiently small plot of ground as being either populated or not populated. A circle with a collateral damage radius for the appropriate weapon is then generated around each possible aimpoint, and the population within is determined. This value is then identified on the map. One thus produces a set of maps for a region, i.e., one set of suitable aimpoints for each of the different weapons under consideration. In addition to maps, transparent overlays for use with 1:50,000 maps of these areas are also generated.

\section{AIMPOINT SELECTION}

Using the process previously outlined, we have a typical output for a region shown in Fig. 1. Figure 2 is for the same region but uses a collateral damage radius corresponding to a larger yield weapon. The dots reflect possible burstpoints that entail no casualties. A quick comparison shows that Fig. 1 has many more points available for aiming a weapon than does Fig. 2, lgnoring, for the present, those points for which there are limited numbers of civilians placed at risk, the availability of an abundance of aimpoints is markedly different in Fig. 1 and Fig. 2. The greater availability of aimpoints must of course be balanced against the smaller lethal area of a lower yield weapon and the requirements for an increased inventory. It is important to use the results in a typical analysis to begin to understand the tradeoffs.

Figures 3 and 4 are repeats of Figs. 1 and 2 with tentative burstpoints located and associated lethal areas shaded. The particular resuits are regiondependent, of course. Furthermore, an area of grciter exteni than $100 \mathrm{~km}^{2}$ is involved in most postulated, typical, tactical nuclear weapon encounters.

A critical question underlies the importance of the selection of possible aimpoints: Has sufficient damage been inflicted on the enemy to make use of the weapons worthwhile? A careful analysis is necessary where the aimpoints are used and weapons are set off in a code that accurately assesses damage to the enemy and civilians. Our assessment codes and aimpoint selection codes are closely related in format so this can be done. A simple and accurate measurement is more quickly achieved by computing the fractional area covered by lethal dosage. This can be accomplished by counting the number of weapons launched, subtracting the overlapping areas using visual estimates, and multiplying the result by the lethal area for one burst.

The results for the pairs of areas illustrated in Figs. 1-4 are summarized in Table I. This example illustrates the case where essentially no civilians were placed at high risk. (The exception is aimpoint coordinates $491.4,5567.2$ of Fig. 4, where $\sim 100$ people are placed at risk.)

Table 1. Results of weapon aimpoint data analyses from Figs. 1-4 (no civilians at high risk).

\begin{tabular}{lcccc}
\hline & \multicolumn{2}{c}{$\begin{array}{c}\text { Weapon effects } \\
\text { radius, } \mathbf{k m}\end{array}$} & & Weapons \\
\cline { 2 - 5 } $\begin{array}{c}\text { Figure } \\
\text { numbers }\end{array}$ & $\begin{array}{c}\text { Collateral } \\
\text { damage }\end{array}$ & Lethal & $\begin{array}{c}\text { Leth.? } \\
\text { used }\end{array}$ & coverage, g \\
\hline 1 and 3 & 1.3 & 1.0 & 20 & $\sim 50$ \\
2 and 4 & 1.7 & 1.3 & 9 & $\sim 35$ \\
\hline
\end{tabular}

\footnotetext{
*An analysis of other studies where we used the detailed knowledge of enemy force locations leads to the conclusion that for the relatively high coverage usually desired ( 25 to $40 \%$ ) the ratio of area subjected to lethal doses compared to total area under consideration is close to the results of detailed tabulations of damage to the enemy forces. This tends to be irue since the size and elfectiveness of an advancing enemy in the regions from a few kilometers to a few tens of kilometers behind the forward edge of battle area (FEBA) has to be one with a spiead-out distribution. The length of the FEBA where intensive cunflict occurs in scenarios of interest tends to be from 10 to $40 \mathrm{~km}$. Depenring on the shape of the FEBA, we are usually concerned with areas that entail 100 to $500 \mathrm{~km}^{2}$ at a given time.
} 


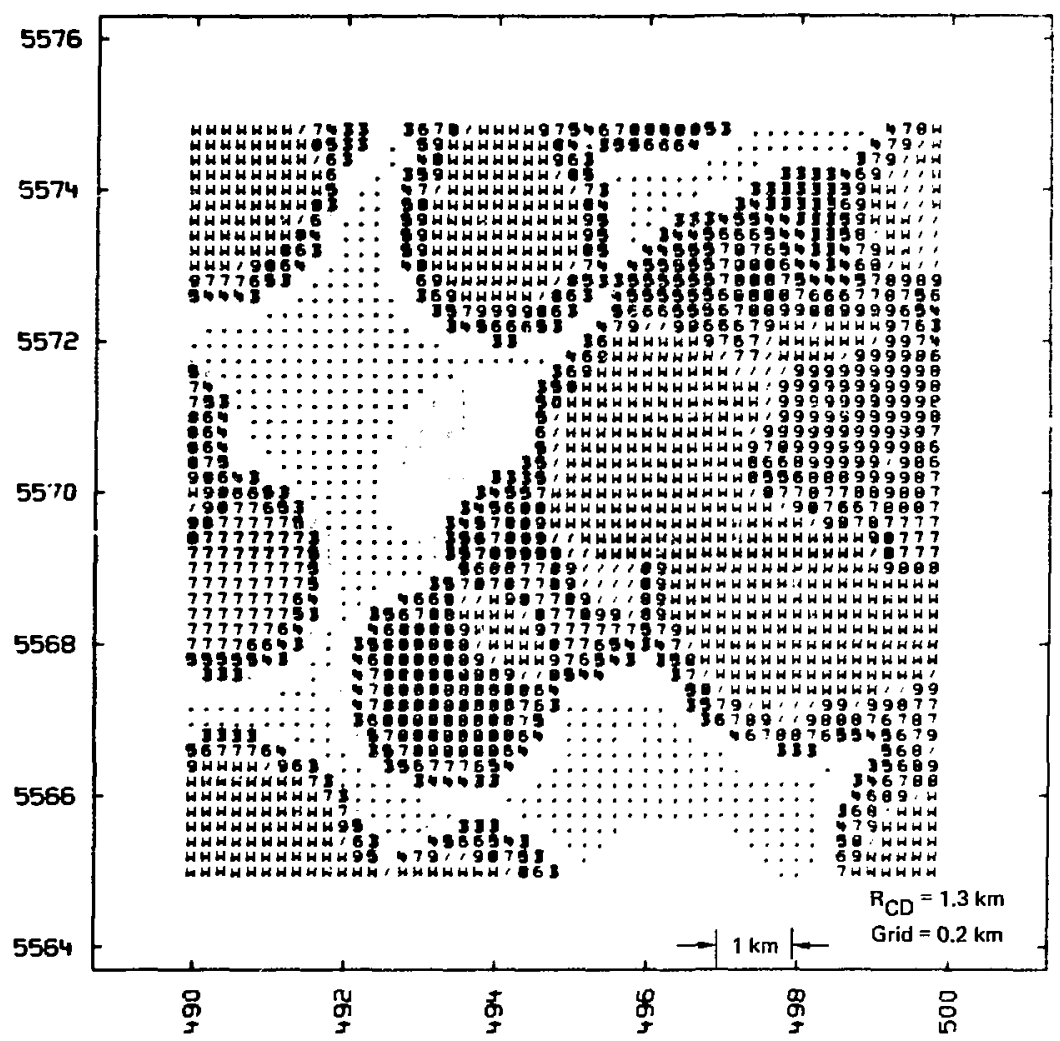

Fig. I. Symbols for the number of civilians at risk for each of 2500 burstpoints in the $10-\mathrm{km}$-hy-10-km region shown. Colloteral damage radius ( $R(n)$ equals $1.3 \mathrm{~km}$. Coordinates are the $1000-m(1-k m)$ UTM grid. Symbols (in color) reflect total casualites:

Blue dot $(\cdot) 0$

Yellow $1 \leqslant 100$

Yellow $2 \leqslant 200$

\author{
Green $3 \leqslant 300$ \\ Green $4 \leqslant 400$ \\ Green $5 \leqslant 500$
}

Purple $6 \leqslant 600$

Purple $7 \leqslant 700$

Purple $8 \leqslant 800$
Purple $9 \leqslant 900$

Purple slash : $/ 1 \leqslant 1000$

Red $\boldsymbol{W}>\mathbf{1 0 0 0}$

\section{DÁTA BASE PREPARATION}

\section{Identifying Populated Areas}

We have chosen a method we believe to be adaptable to the most dynamic utilization of new population data. Use can be made of the most current maps of the regions under consideration. We have chosen to use the most recent $1: 50,000$ maps available to us for the areas under study because they are sufficent to allow the identification of the actual buildings in the regions.

The external contours of the population centers are drawn and then digitized. Figures 5 and 6 reflect the contours from the digitized data for two typic. : towns. The equipment used to digitize the contours has an inherent accuracy greater than that in the 


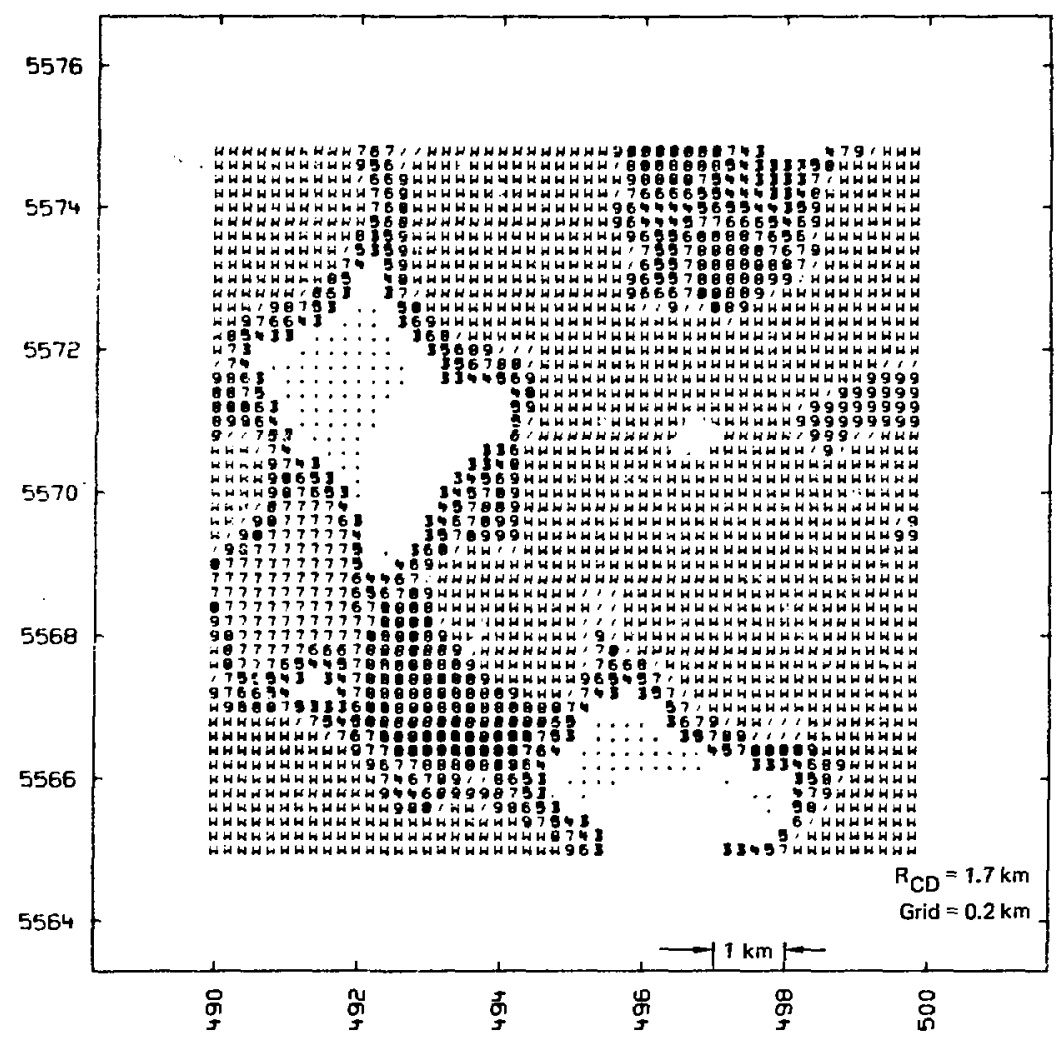

Fï. 2. Symbols for the numbers of civilians at risk for each of 2500 busstpoints in the 10-km-by-10-km region shown. Collateral damage radius ( $R_{(D)}$ eguals $1.7 \mathrm{~km}$. Coordinates are the $1000-m(1-\mathrm{km})$ (ITM grid. Symbols (in color) reflect total casualties and, as in Fig. 1 . represent the upper-bound of civilians at risk in hundreds.

map or in the contour around a town. Once the contours where people exist have been created and digitized, each $20-m$ area is tagged as being populated or not populated, depending on whether more or less that $50 \%$ of the area is included in the contour. A determination is then made on a $100-m-b y-100 \rightarrow m$ grid as to whether there is a majority of populated $20-m-b y-20-m$ squares. The $100-\mathrm{m}$-by-100-m squares, or hectares (ha), are thus identified as either populated or nor populated.
Figures 7 and 8 are examples for the towns shown in Figs. 5 and 6 . A data base is then constructed that contains the coordinates of the center of all populated hectares.

Comparisons have been made with other population data bases that are common with correlations that exist between town populations and areas. We have found 25 to 35 people per hectare in the regions identified as populated. Obviously, differences arise depending on the size of the city and if 


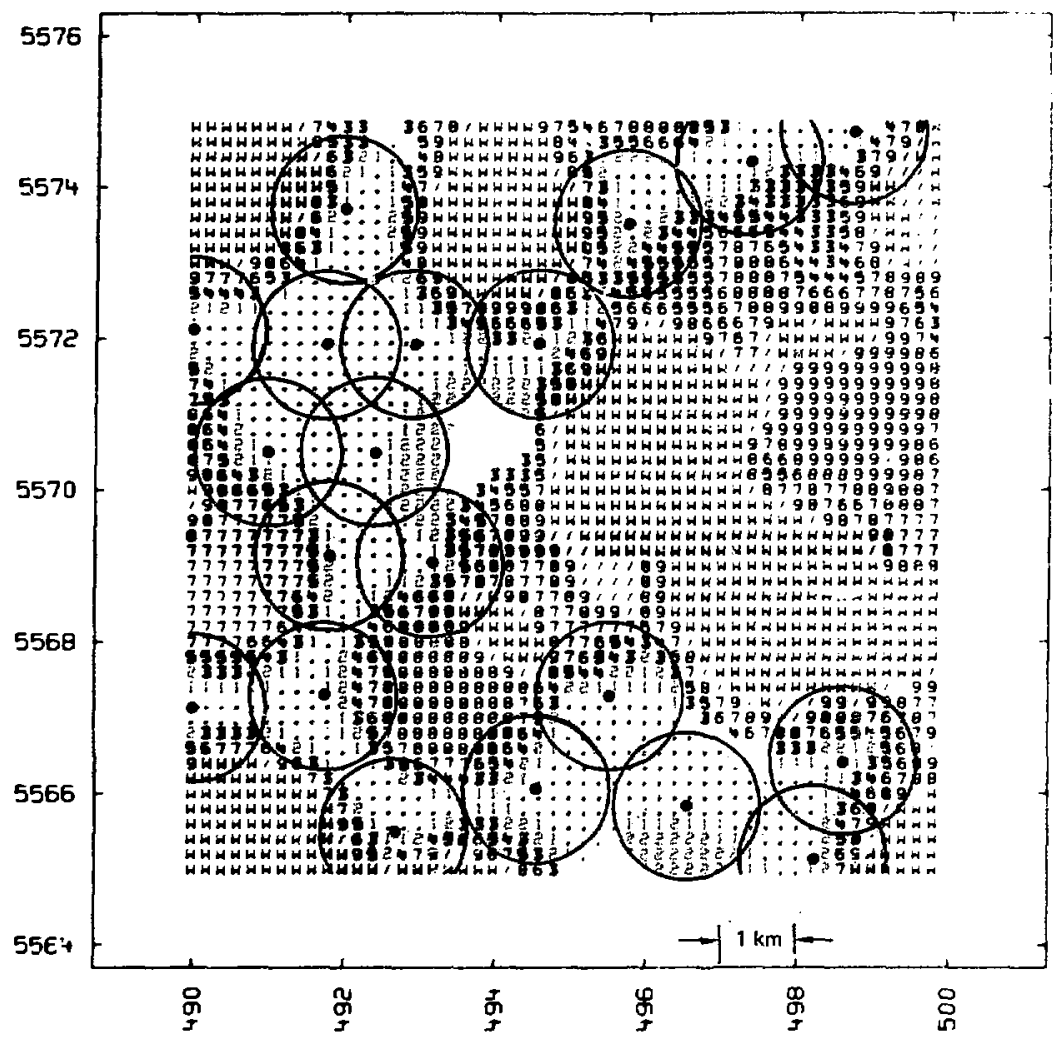

Fig. 3. Same 10-km-by-10-km region as shown in Fig. 1 with tentative burstpoints tocited and associated lethal areas shaded. $R_{(1)}=1.3 \mathrm{~km}$. Coodinates are the 1000-m (1-km) ( TM1 grid. Symbols (in color) reflect tutal casualties and, as in Fig. 1, represent the upper-bound of civilians at risk in hundreds.

it contains apartments. Since sizeable towns will usually be avoided, we are primarily interested in snall towns and the outskirts of larger cities.

For the results shown in this report, we have used a 25-person-per-hectare conversion facior. We could provide more sophisticated detsiling if necessary; similarly, an industrial value could be added to the hectare under consideration. At present the basic unit is an occupied hectare, which we translated into a population figure primarily for easier correlation with previous studies.

\section{Data Manipulation}

The total data generated by the method presented in the previous section soon becomes immense. Since we studied those areas of greatest interest first to test feasibility of the method. we did not accumulate the data in a simple sequential manner.

We developed several minor codes to check and sort the data. Since all essential data used after completing the digitizing precess is the accumulation of the centers of occupied hectares, we now perform a check to determine if duplicate data exists. A data 


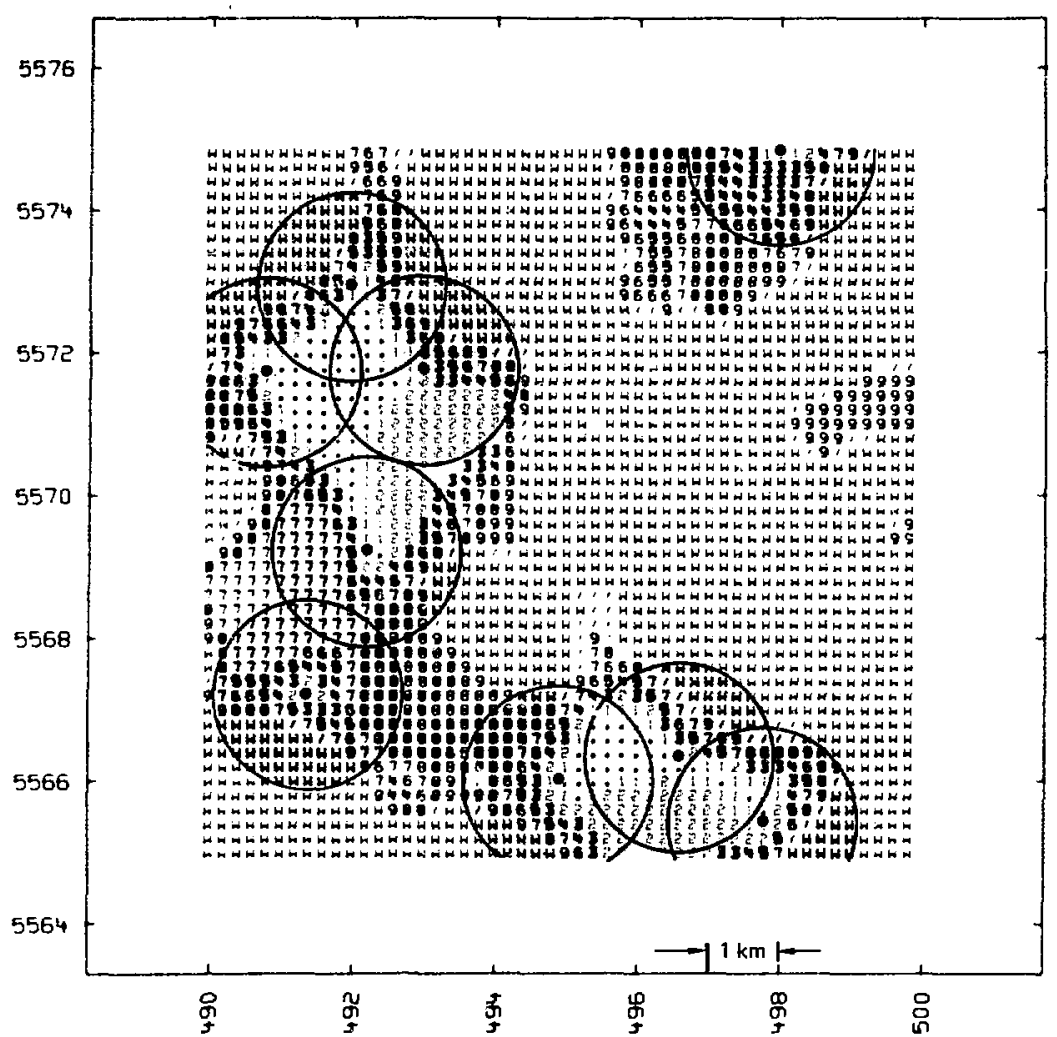

Fig. 4. Same 10-km-by-10-km region as shown in Fig. 2 with tentative burstpoints located and associated Jethal areas shaded. $R_{1,}=1.7 \mathrm{~km}$. (oordinates are the $1000-m(1-\mathrm{km})$ UTM grid. Symbols in color) reflect fotel casualties and, os in Fig 1 , represent the upper-bound of civilians at rish in hundreds.

poini, therefore, appears only once. We perform this check periodically on our total data base as we add information from different sets of digitized data.

We use another code to restrict the data examined to that needed to perform the calculations in the region under study. These two steps allow us to continually add to our data base and make relatively short calculations when we wish to study a given area.

\section{Extent of the Data Base}

Early efforts to digitize the maps were focused on regions where maps were conveniently available and where previous detailed studies on military effectiveness had been made.

The prime data base is almost complete for an $80-\mathrm{km}$-by-80-km region (UTM coordinates 480 to 560,5560 to 5640), which includes Fulda, West Germany and extends westward almost to Frankfurt, 


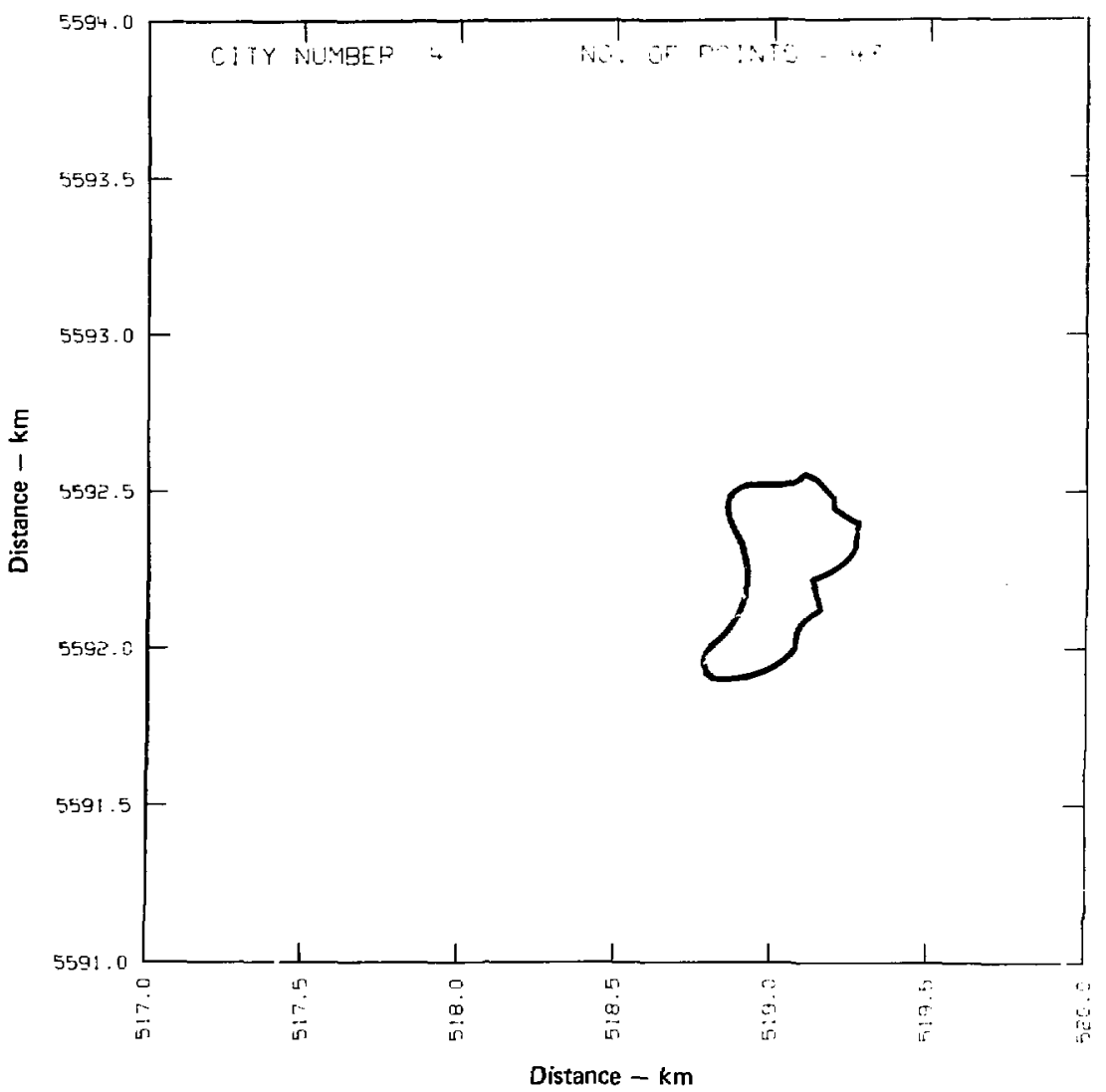

Fig. 5. Extemal contour of a typical small town.

West Germany. This is the region used extensively in work done at Lawrence Livermore Laboratory (LLU) for studies in cooperation with the U.S. Army and the U.S. Air Force.
Rapid additions can be made to the data base as appropriate maps become available for other regions of interest: or alternately, new and updated information can be introduced into the data base. 


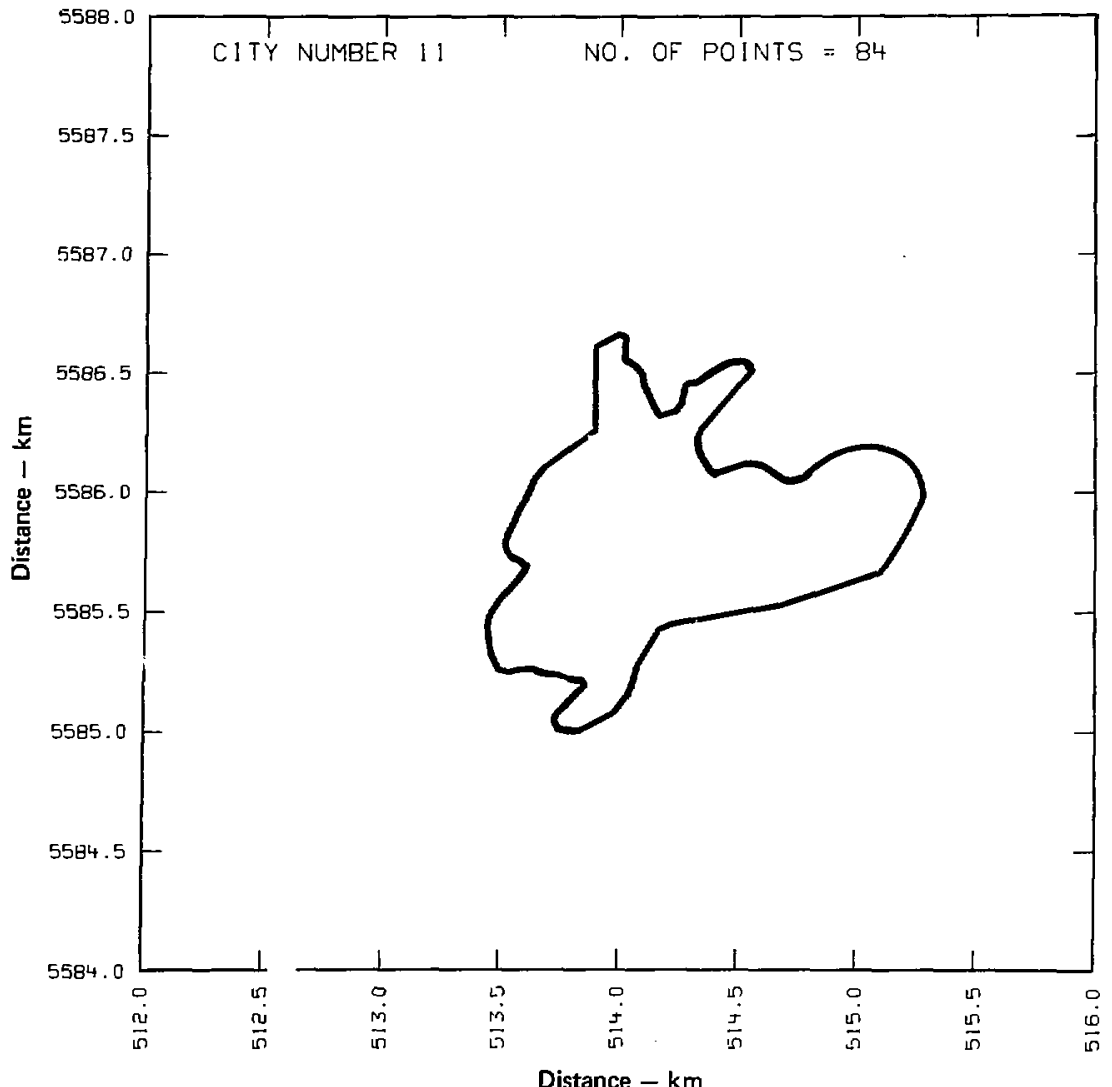

Fig. 6. External contour of a typical large town.

\section{USEFUL OUTPUT PARAMETERS}

As we discussed in the previous section, a granularity of the data on a hectare-by-hectare basis was chosen. The quality of the basic data and the steps to put it into a usable form matched this choice. The resultant data bases are not tou large to preclude easy manipulation.
The collateral damage radii of weapons chosen for study, the adaptability of the output to a relatively easy interpretation and use, and the constraints of having a relatively fast code have an effect on the arbitrary choice of useful parameters. Most of our studies have been made by restricting 


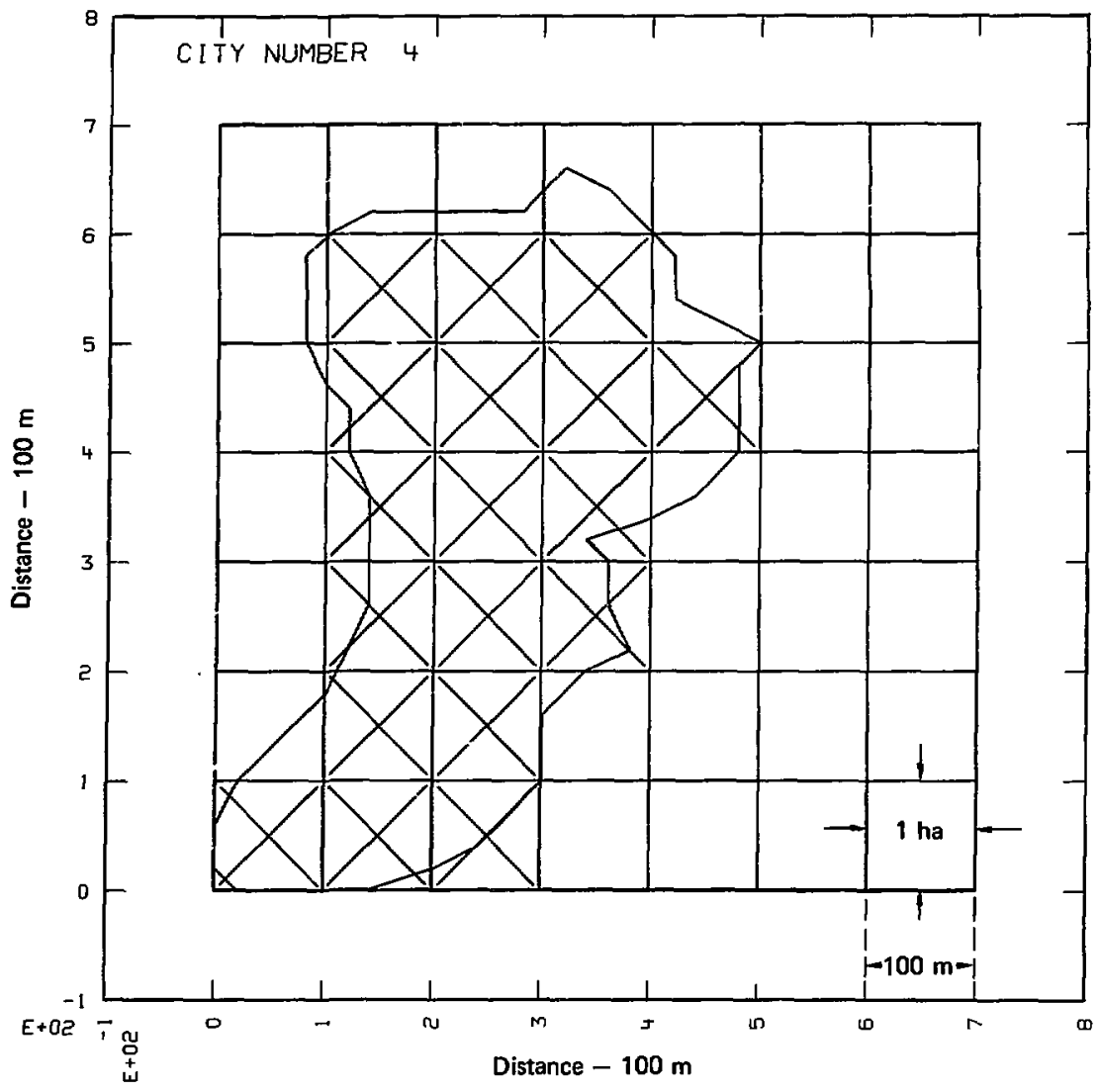

Fig- 7. Populated hectares of typicsl small town shown in Fig. 5.

our examination of possible aimpoints to those ihat oceur at $200-\mathrm{m}$ intervals. In a $10-\mathrm{km}-\mathrm{by}-10-\mathrm{km}$ region, we total the civilian casualties for each of 2500 burstpoints. A single integer can then be displayed on this $200-m$ grid. It is legible for most useful sizes of output, and it is adequate to indicate the number of civilians at risk over the ranges of interest. The gradient in the number of civilian casualties is discernible as one moves through a given region.
Choices were made to display the results numerically that related to past practices in collateral damage studies. Usually all cities greater than 1000 were avoided in previous studies, and that breakpoint is identifjed with a $W$. We have also chosen to identify people in increments of 100 . The value of 25 is the population for a single populated hectare. 


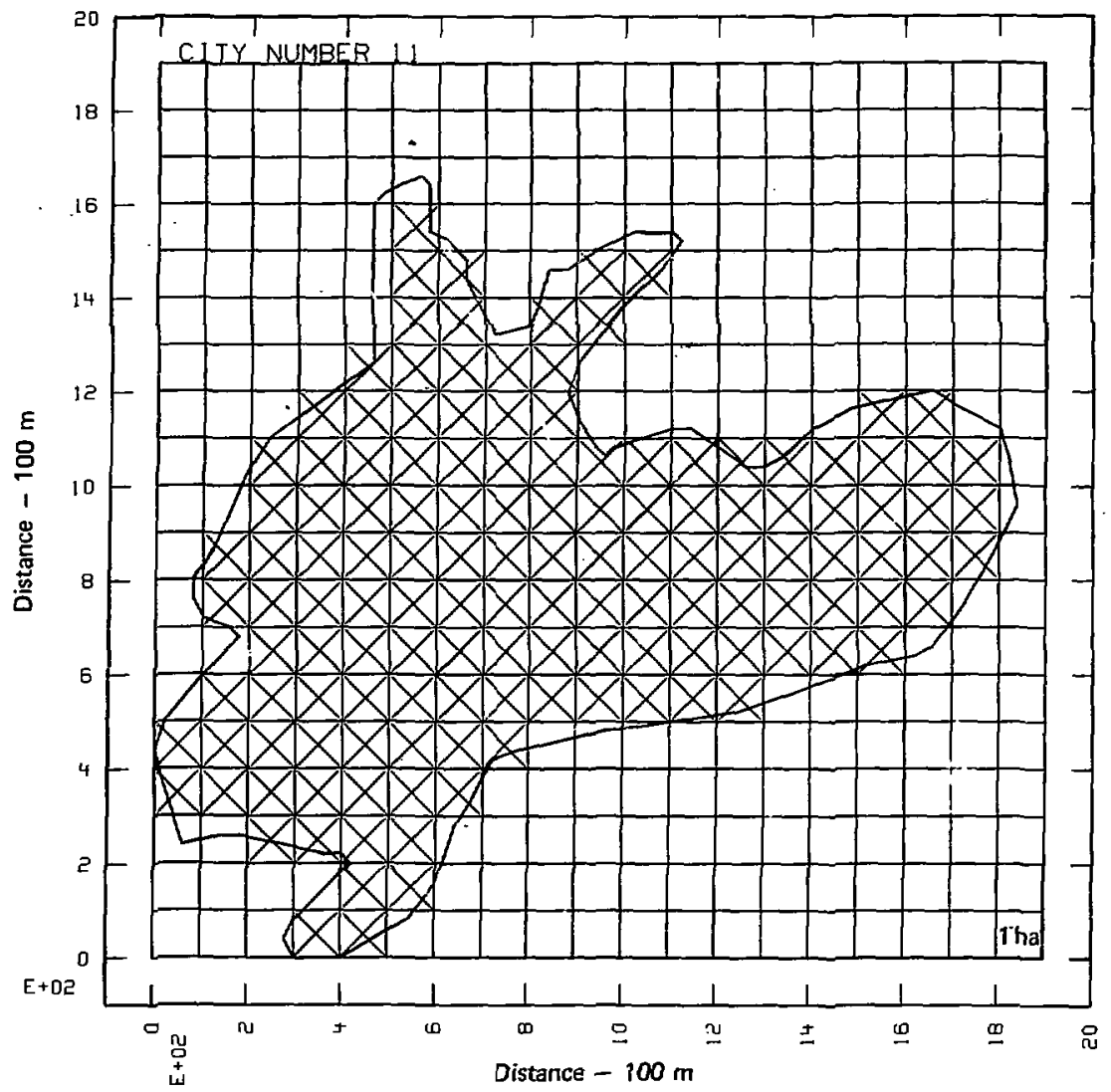

Fig. 8. Populated hectares of typical large town shown in Fig. 6.

\section{OUTPUT FORM VERSATILITY}

The form in which the results are available relate directly to its usefulness in conducting studies. Tabular data in written form are undesirable. There are two modes of color graphics output in addition to a numerical black and white output. Initial output is on colored $35-\mathrm{mm}$ film. Transparent overlays to I:50,000 maps are available in both color and black.

For extensive use of the data in subsequent studies, computer files are generated that serve as inputs to other codes. The numerical displays shown in Figs. 1 and 2 can be displayed on a TV 
screen. We have developed the codes where the selection of aimpoints, drawn with lethal radius circles, are interactively selected. A "joystick" moving a point of light around the screen allows the operator to select aimpoints, the lethal area circles are displayed, and a file is created containing the coordinates of the aimpoints. Tirese files are used to locate the burstpoints for input in the DWEEPS cades. 